\title{
BMJ Open Cardiovascular risk factors-using repeated cross-sectional surveys to assess time trends in socioeconomic inequalities in neighbouring countries
}

\author{
John Hughes, ${ }^{1}$ Zubair Kabir, ${ }^{2}$ Frank Kee, ${ }^{1}$ Kathleen Bennett ${ }^{3}$
}

To cite: Hughes J, Kabir Z, Kee $\mathrm{F}$, et al. Cardiovascular risk factors-using repeated cross-sectional surveys to assess time trends in socioeconomic inequalities in neighbouring countries. BMJ Open 2017;7:e013442. doi:10.1136/bmjopen-2016013442

- Prepublication history for this paper is available online. To view these files please visit the journal online (http://dx.doi.org/10.1136/ bmjopen-2016-013442).

Received 12 July 2016 Revised 21 October 2016 Accepted 16 November 2016

\section{W CrossMark}

${ }^{1}$ UKCRC Centre of Excellence for Public Health, Queen's University, Belfast, UK ${ }^{2}$ Department of Epidemiology \& Public Health University College Cork, Cork, Ireland ${ }^{3}$ Population Health Sciences Division, RCSI St Stephen's Green, Dublin, Ireland

Correspondence to Dr Kathleen Bennett; kathleenebennett@rcsi.ie

\section{ABSTRACT}

Objectives: This study compares trends in socioeconomic inequalities related to key cardiovascular risk factors in neighbouring countries Northern Ireland (NI) and the Republic of Ireland (Rol).

Design: Repeated cross-sectional studies.

Setting: Population based.

Participants: $3500-4000$ in national surveys in $\mathrm{NI}$ and 5000-9000 in Rol, aged 20-69 years.

Measures: Educational attainment was used as a socioeconomic indicator by which the magnitude and direction of trends in inequalities for smoking, diabetes, obesity and physical inactivity in $\mathrm{NI}$ and Rol were examined between 1997/1998 and 2007/2011. Gender-specific relative and absolute inequalities were calculated using the Relative Index of Inequality (RII) and Slope Index of Inequality (SII) for both countries.

Results: In both countries, the prevalence of diabetes and obesity increased whereas levels of smoking and physical inactivity decreased over time. In NI relative inequalities increased for obesity (RII 1.1 in males and 2.1 in females in 2010/2011) and smoking (RII 4.5 in males and 4.2 in females in 2010/2011) for both genders and absolute inequalities increased for all risk factors in men and increased for diabetes and obesity in women. In Rol greater inequality was observed in women, particularly for smoking (RII 2.8 in 2007) and obesity (RII 8.2 in 2002) and in men for diabetes (RII 3.2 in 2002).

Conclusions: Interventions to reduce inequalities in risk factors, particularly smoking, obesity and diabetes are encouraged across both countries.

\section{INTRODUCTION}

Since the mid-1980s Coronary Heart Disease (CHD) mortality rates have more than halved in Ireland, as in many other countries in Western Europe. ${ }^{12}$ Although age-specific CHD mortality rates are decreasing, population ageing is expected to increase future levels of CHD incidence and mortality. ${ }^{3}$ These predicted increases for future CHD prevalence coupled with recent evidence of

\section{Strengths and limitations of this study}

- Strengths of the study include:

- The nationally representative repeated crosssectional surveys in Northern Ireland (NI) and the Republic of Ireland (Rol). Prevalence of cardiovascular risk factors was compared, stratified by educational level.

- Educational attainment was used as a socioeconomic indicator by which the magnitude and direction of trends in inequalities for smoking, diabetes, obesity and physical inactivity in NI and Rol were examined.

- The limitations were that the study populations only included those aged to 20-69 years and complete information was not available on all risk factors for cardiovascular disease.

levelling-off in cardiovascular disease (CVD) mortality in Ireland highlight the importance of building on existing public health initiatives that are helping to reduce population levels of risk factors such as smoking and diabetes. ${ }^{4}$ Further reductions in risk factors such as cholesterol, high blood pressure and smoking have consistently explained $>50 \%$ of CHD mortality declines in Ireland ${ }^{12}$ and elsewhere. ${ }^{5}$

One of the most challenging issues for disease prevention is the need to address health inequalities and their social determinants. ${ }^{6}$ In Western industrialised countries, higher rates of CVD mortality and associated adverse risk factor prevalence are disproportionately found in lower socioeconomic groups. ${ }^{7}$ Northern Ireland (NI) is recognised as having some of the greatest levels of health and social inequalities in the $\mathrm{UK}^{8}$ but was one of the first countries to adopt an interdepartmental approach to devise comprehensive strategies to combat them. An overarching public health policy ${ }^{9}$ has given a renewed commitment to reducing challenging health inequalities ${ }^{10}$ by addressing the 
wider social determinants of health such as education, poverty, social exclusion and making healthy lifestyle choices. In the Republic of Ireland (RoI) a 10-year National Action Plan for Social Inclusion 2007-2016 ${ }^{11}$ was published and specific targets for the reduction of health inequalities were identified in 2001 and endorsed in the National Health Strategy, Quality and Fairness: A Health System for You. ${ }^{12}$

Previous work has provided some insight on socioeconomic differentials in the long-term risk of CHD in Northern Irish men, ${ }^{13}$ with similar significant socioeconomic differences in CHD mortality in NI and RoI, ${ }^{14}$ and a recent study has reported on the CVD mortality differentials between NI and England. ${ }^{15}$

In the present study we provide an assessment of trends in gender-specific cardiovascular risk factors, between 1997 and 2011, and associated socioeconomic changes in two neighbouring countries, NI and RoI, with similar populations but different public health policies and separate healthcare systems. The aim of the study was to assess the magnitude, direction and changes in the prevalence of modifiable risk factors for CVD according to educational attainment, as a proxy measure for socioeconomic status, in NI and RoI, using comparable national health surveys from 1997-2011.

\section{METHODS}

\section{Survey method and sample}

Data on cardiovascular risk factors and on individual educational attainment characteristics were obtained from repeated cross-sectional health surveys in NI and RoI from 1997 to 2011. These nationally representative health surveys from NI (1997, 2001, 2005/2006 and 2010/2011) and in RoI (1998, 2002 and 2007) are periodically undertaken for ongoing surveillance of population health and lifestyle behaviours in both countries. The NI surveys were commissioned by the Department of Health, Social Services and Public Safety in NI and all such surveys are covered by the Code of Practice for
Official Statistics in NI. The nationally representative cross-sectional health surveys (response rates $>60 \%$ ) have been described in detail elsewhere. ${ }^{15}{ }^{16}$ Health surveys in NI are based on face-to-face interviews in private residences. The 2007 SLÁN (Survey of Lifestyle, Attitudes and Nutrition) survey in RoI was based on face-to-face interview with earlier waves in 1998 and 2002 based on a self-completed postal questionnaire.

As educational attainment was only asked of respondents under the age of 70 in NI in 2005/2006 our analyses were restricted to persons aged 20-69 in both jurisdictions. This translated into samples of 3375, 3751, 3374 and 3239 respondents in NI in 1997, 2001, 2005/ 2006 and 2010/2011, respectively, and samples of 5104, 4627 and 8707 respondents in RoI in 1998, 2002 and 2007, respectively.

\section{Definitions of cardiovascular risk factors}

Individual cardiovascular risk factors were chosen to ensure maximum comparability between NI and RoI and between survey years. Dichotomous variables were derived to indicate the presence or absence of a risk factor (table 1). For diabetes, self-reported diagnosis was recorded if the respondent had ever been told by a doctor of a diagnosis of diabetes. Smoking prevalence was based on being a current smoker. Using recognised physical inactivity questionnaires, ${ }^{17}{ }^{18}$ a respondent was classified as physically inactive if they had not met recommended guidelines of performing at least moderate activity lasting $30 \mathrm{~min} /$ day on $\geq 5$ occasions/week. The obesity measurement for NI was computed from anthropometric height and weight measurements (1997, 2005/2006 and 2010/2011). In RoI, obesity data were generated from self-reported height and weight information. Obesity was defined as body mass index (BMI) $\geq 30 \mathrm{~kg} / \mathrm{m}^{2}$ using the WHO criteria. $^{19}$ Blood pressure and total cholesterol measures were not available across all time points and therefore are not included.

\begin{tabular}{|c|c|c|c|}
\hline \multirow[b]{2}{*}{$\begin{array}{l}\text { CVD } \\
\text { risk factor }\end{array}$} & \multirow[b]{2}{*}{ Definition/description } & \multicolumn{2}{|l|}{ Years available } \\
\hline & & Northern Ireland & $\begin{array}{l}\text { Republic of } \\
\text { Ireland }\end{array}$ \\
\hline Smoking & $\begin{array}{l}\text { Current smoker (smoking 'everyday' or 'some days', } \\
\text { and 'having smoked at least } 100 \text { cigarettes during my } \\
\text { lifetime') }\end{array}$ & $1997,2001,2005 / 2006,2010 / 2011$ & $1998,2002,2007$ \\
\hline Diabetes & $\begin{array}{l}\text { Self-reported doctor diagnosed 'ever' diagnosis } \\
\text { (excludes pregnancy only cases) }\end{array}$ & $1997,2001,2005 / 2006,2010 / 2011$ & 1998, 2002 \\
\hline Obesity & Measured $\left(\mathrm{BMI} \mathrm{kg} / \mathrm{m}^{2}>30\right)$ & $1997,2005 / 2006,2010 / 2011$ & \\
\hline Obesity & $\begin{array}{l}\text { Self-reported height and weight measurements used to } \\
\left.\text { calculate BMI (obesity =BMl }\left(\mathrm{kg} / \mathrm{m}^{2}\right)>30\right)\end{array}$ & & 1998, 2002, 2007 \\
\hline $\begin{array}{l}\text { Physical } \\
\text { inactivity }\end{array}$ & $\begin{array}{l}\text { Not meeting recommendations of } \geq 5 \text { occasions/week } \\
\text { of at least moderate activity (for at least } 30 \mathrm{~min} / \text { day) }\end{array}$ & $2001,2005 / 2006,2010 / 2011$ & 1998, 2002 \\
\hline
\end{tabular}




\section{Definition of socioeconomic variable}

Educational attainment, a widely recognised proxy indicator for socioeconomic position, was used in the analyses, as it can be recorded for all respondents irrespective of employment status. ${ }^{20}$ Respondents were assigned to one of three educational attainment categories namely, primary (first level, usually to age 11-13 years; this is equivalent to 6-8 years of school from age 5), secondary (second level, usually to age 18 years; this is equivalent to 13 years of school in total) and third level (degree level or higher educationundergraduate or postgraduate level).

\section{Statistical analysis}

Gender-specific risk factor prevalence according to educational attainment was age standardised using 10 year age bands by the direct method and using the European standard population (see figures 1 and 2).

\section{Calculation of inequality measurements}

As recommended in the literature, a generalised least squares approach was used $^{21}$ to calculate absolute and relative socioeconomic inequalities for each risk factor. First, a 'ridit' variable was computed for each survey by hierarchically ranking educational attainment status from highest to lowest. A ridit score is calculated for each educational attainment stratum by calculating the mean proportion of the population with a higher level of educational attainment. For example, if 30\% and $40 \%$ of the population have attained primary-level and secondary-level education, respectively, and using midpoints for the proportion of the population in each category, the ridit score for those with primary-level education only would be 0.15 and $0.3+(0.4 / 2)=0.5$ for those attaining secondary-level education.

\section{Absolute inequalities}

Generalised linear models were used $^{21}$ to generate estimates of the Slope Index of Inequality (SII) using a logbinomial maximum likelihood approach regressing age standardised prevalence of a cardiovascular risk factor on the ridit score and 10 year age groups. Using an identity link function, the SII estimates (coefficient of ridit) represented the rate difference taking into account the distribution of all three educational attainment groups. The greater the value of SII, the greater the extent of absolute inequality. A SII of (near to) 0 indicates that the cardiovascular risk factor is not subject to any inequality.

\section{Relative inequalities}

For relative inequalities, generalised linear models were fitted using a logarithmic link function. ${ }^{22}$ The coefficient of ridit estimated the Relative Index of Inequality (RII) or prevalence ratio difference between the two extremes of the educational attainment hierarchy. An RII $>1$ indicates a higher mean prevalence rate of the selected risk factor (eg, being a smoker) among the lowest educated category compared with the highest educated category. An RII $<1$ indicated a higher mean prevalence rate for the selected risk factor among the highest educated category.

To assess time trends in SII and RII, models were fitted with an interaction term of survey year $*$ ridit score. A $p$ value of $<0.05$ for the interaction term was indicative of significant change in the inequality measure over time. Differences in gender-specific SII and RII for each survey year and over time were also assessed by incorporating appropriate two way and three way interaction terms respectively. Analyses were weighted to account for individual survey sample design and non-response. Analyses were carried out using STATAV.11.2 (StataCorp, 2009).

\section{RESULTS}

The characteristics of the health surveys from each jurisdiction are presented in table 2. The distributions of demographic and socioeconomic variables and conventional cardiovascular risk factors were broadly comparable between NI and RoI.

Figures 1 and 2 provide gender-specific age standardised prevalence of risk factors across educational attainment categories for available years for NI and RoI respectively.

\section{Diabetes and obesity}

There were increasing trends with respect to diabetes and obesity with overall prevalence increasing in both countries over the study period. Diabetes prevalence and obesity levels increased in NI for both genders in each educational category over the lifetime of the study. In general for RoI, diabetes and obesity levels increased for all educational subgroups for both genders.

\section{Smoking}

There were marked decreases in the prevalence of smoking in both countries. In NI, there were substantial declines in smoking prevalence for all gender stratified educational groups apart from among women with secondary-level education. In RoI, over the study period, there were decreases in smoking levels among third-level and secondary-level education categories. However, there were marked increases in smoking levels for both genders in those with only primary-level education.

\section{Physical inactivity}

The proportion of the samples that were in the highest level of educational attainment increased over time in both countries. Physical inactivity levels fell markedly in NI over the study period and decreases were found for both genders in all educational groups. Physical inactivity levels decreased among all men in RoI which is in contrast to women where increases in inactivity among the primary education group were apparent, as well as decreases in activity among women with third-level education. 
Males

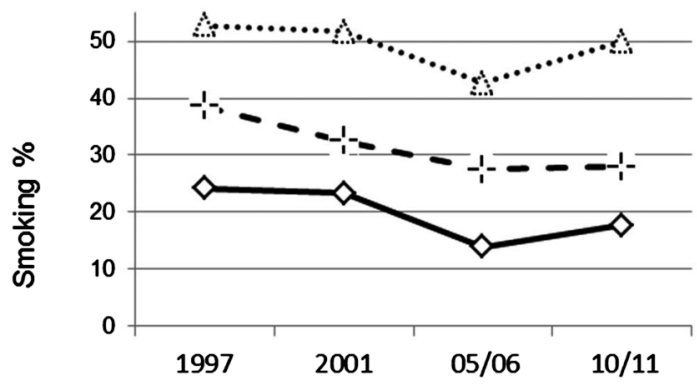

$\longrightarrow$ Third _ - S Secondary ...... Primary
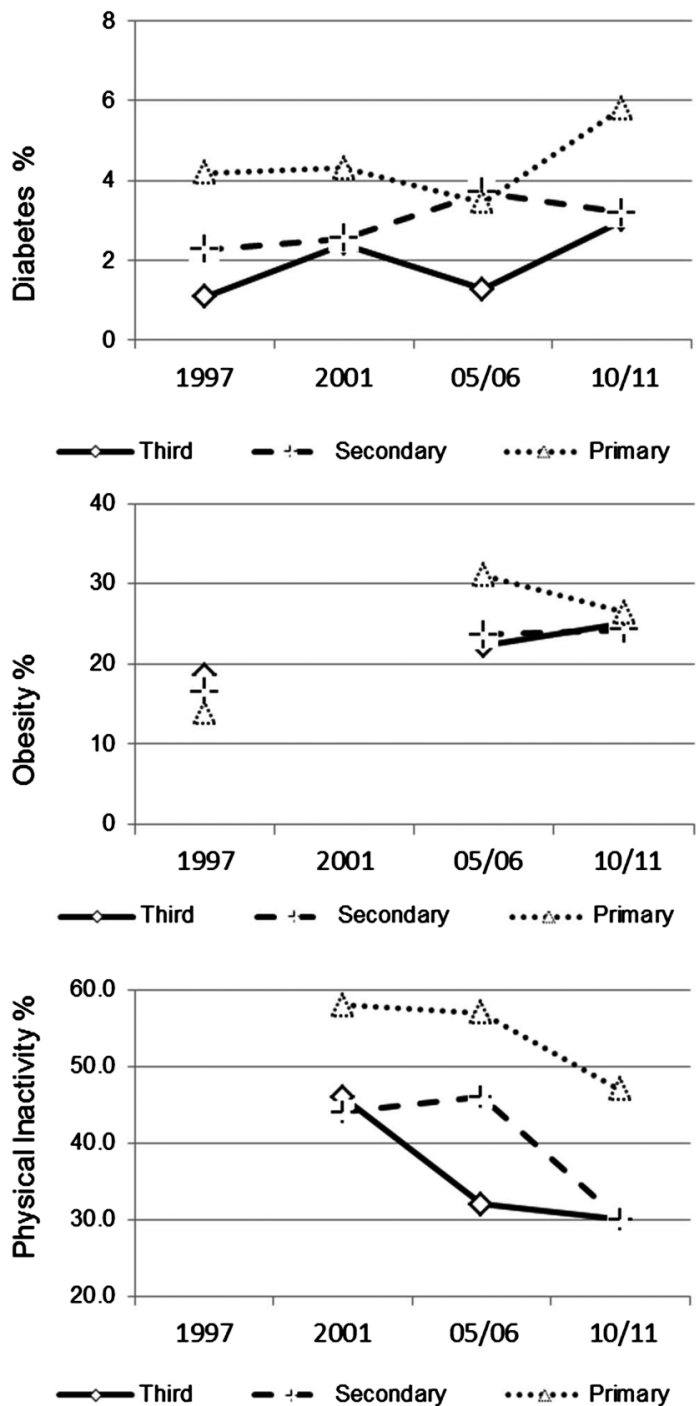

Females


Figure 1 Trends in age standardised prevalence of smoking, diabetes, obesity and physical inactivity, by gender, for persons aged 20-69, in NI. NI, Northern Ireland.

Slope Index of Inequality (SII) and Relative Index of Inequality (RII)

Table 3 provides gender-specific measurements for SII and RII by survey year for NI and RoI and associated tests for linear trend over time.

\section{Smoking}

There is evidence of increasing relative inequalities in smoking in NI over the period 1997-2010 for men $(p=0.01)$. A fourfold higher smoking rate was reported among the least educated relative to the most educated 
Figure 2 Trends in age standardised prevalence of smoking, diabetes, obesity and physical inactivity, by gender, for persons aged 20-69, in Rol. Rol, the Republic of Ireland.
Males

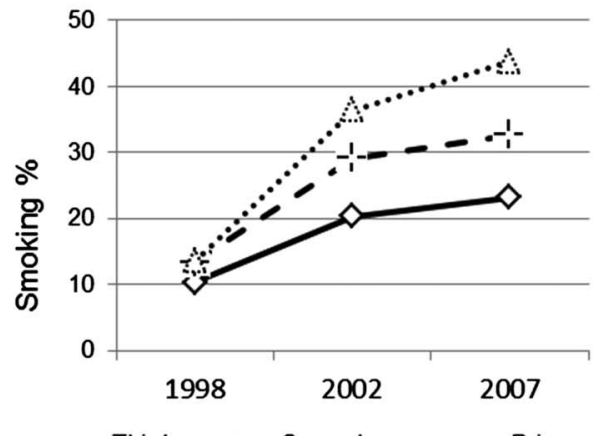

$\longrightarrow$ Third _ - Secondary ....... Primary
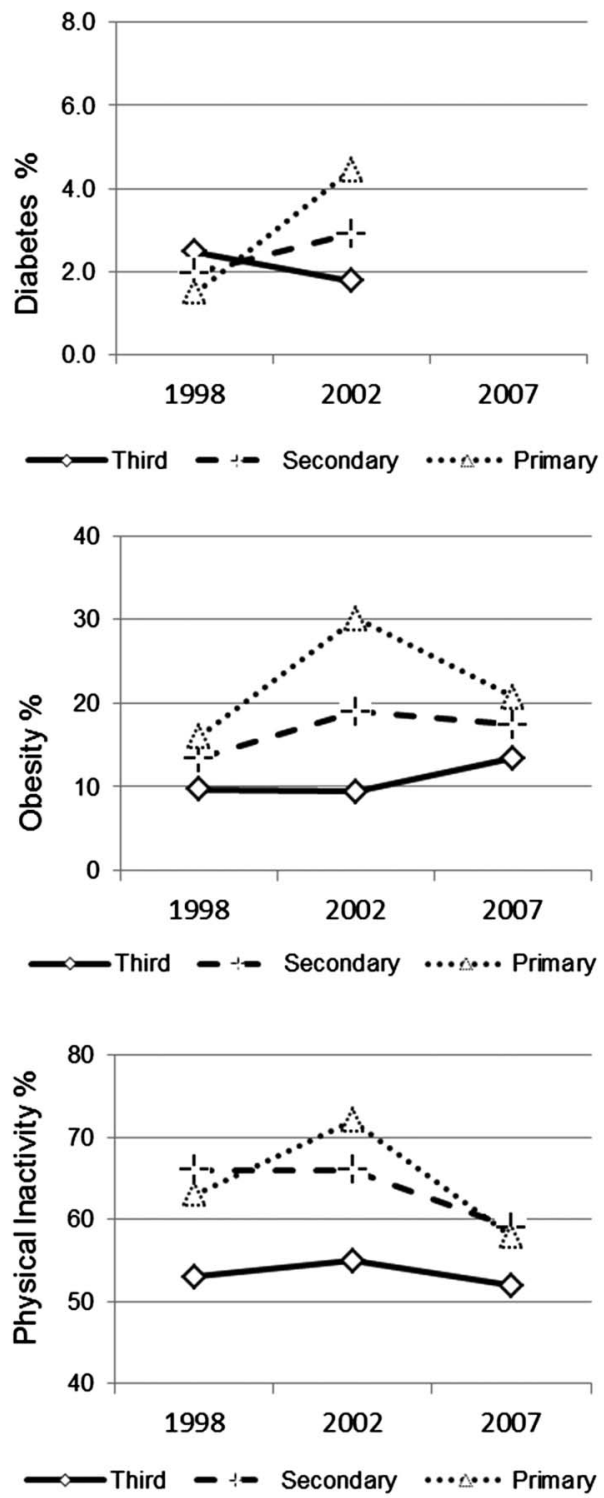

Females
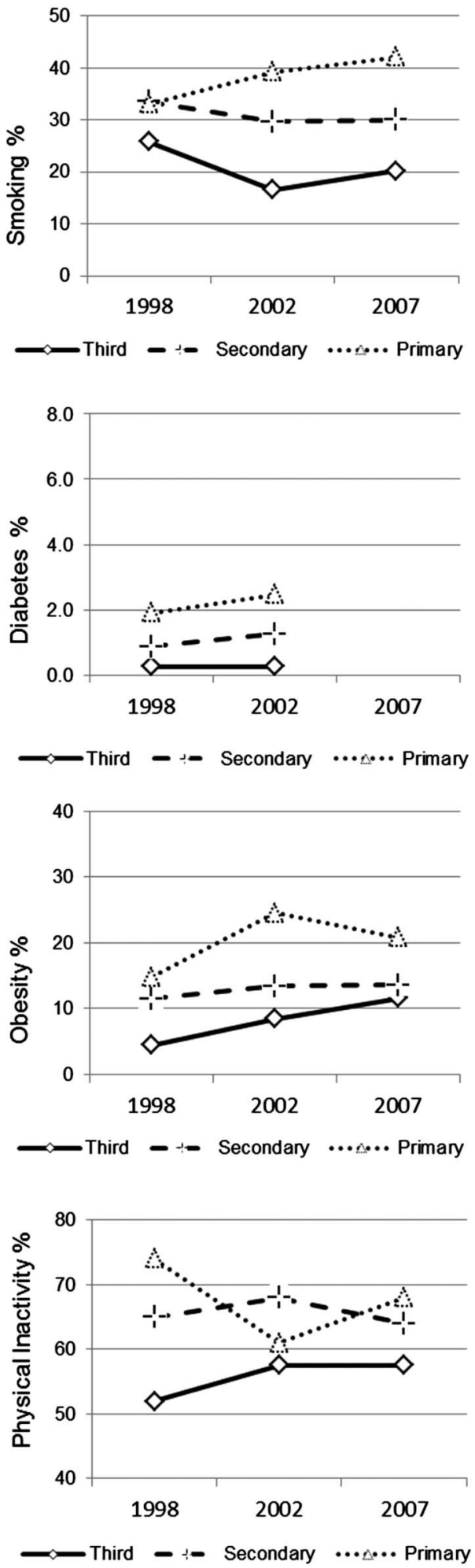

in NI across both sexes in the most recent year. Absolute inequalities in smoking in RoI narrowed for both genders between 1998 and 2007 (consistent with decreasing prevalence). Relative inequalities for smoking in RoI were stable in men but increased significantly in women $(p=0.02)$ between 1998 and 2007. Gender differences were apparent $(p=0.01)$ with relative inequalities higher in women than men in 2002 and 2007.

Diabetes and obesity

There were no significant changes in absolute or relative inequalities in NI for diabetes prevalence over the study 
Table 2 Characteristics of the population (numbers and \%) from health surveys ${ }^{*}$ in Northern Ireland and in the Republic of Ireland

\begin{tabular}{|c|c|c|c|c|c|c|c|c|}
\hline & & \multicolumn{4}{|c|}{ NI health surveys $\ddagger$} & \multicolumn{3}{|c|}{ Rol health surveys $\ddagger$} \\
\hline & & 1997 & 2001 & $2005 / 2006$ & $2010 / 2011$ & 1998 & 2002 & 2007 \\
\hline Sample size & & 3375 & 3751 & 3374 & 3239 & 5104 & 4627 & 8707 \\
\hline \multirow[t]{2}{*}{ Gender } & Males & $42.5(1435)$ & $42.6(1599)$ & $41.4(1396)$ & $40.7(1317)$ & $47.0(2401)$ & 40.9 (1893) & 41.9 (3648) \\
\hline & Females & $57.5(1940)$ & $57.4(2152)$ & 58.6 (1978) & 59.3 (1922) & $53.0(2703)$ & $59.1(2734)$ & $58.1(5059)$ \\
\hline \multirow[t]{3}{*}{ Smoking } & No & 64.9 (2189) & $67.7(2538)$ & $71.4(2410)$ & $74.2(2404)$ & $66.6(3377)$ & 72.7 (3362) & 69.8 (6079) \\
\hline & Yes & $35.1(1186)$ & $32.3(1213)$ & 28.5 (963) & $25.8(835)$ & $32.1(1640)$ & $26.5(1224)$ & $29.0(2526)$ \\
\hline & & & & $0.0(1)$ & & $1.7(87)$ & $0.9(41)$ & $1.2(102)$ \\
\hline \multirow[t]{3}{*}{ Diabetes } & No & 97.6 (3295) & $97.5(3657)$ & 96.9 (3270) & $95.6(3095)$ & 98.3 (5019) & $96.9(4485)$ & - \\
\hline & Yes & $2.4(80)$ & $2.5(94)$ & $3.1(104)$ & $4.4(144)$ & 1.7 (85) & $2.1(99)$ & - \\
\hline & Missing & - & - & - & - & - & $0.9(43)$ & - \\
\hline \multirow[t]{3}{*}{ Obesity } & $\mathrm{BMl}<30$ & $30.6(1032)$ & - & $57.1(1925)$ & $47.5(1540)$ & $83.9(4284)$ & 79.8 (3694) & $70.4(6128)$ \\
\hline & $\mathrm{BMI} \geq 30$ & $7.8(262)$ & - & $20.4(688)$ & $16.0(517)$ & $10.2(519)$ & $13.3(616)$ & $13.0(1132)$ \\
\hline & Missing & $61.7(2081)$ & - & $22.6(761)$ & $36.5(1182)$ & $5.9(301)$ & $6.9(317)$ & 16.6 (1497) \\
\hline \multirow[t]{3}{*}{ Physical inactivity* } & No & & 49.9 (1833) d(33 115) & 51.7 (1744) (17 612 815) & 59.6 (1932) & $39.6(2020)$ & $36.3(1680)$ & 40.2 (3499) \\
\hline & Yes & & $51.1(1916)$ & $48.3(1630)$ & 39.9 (1293) & $60.4(3084)$ & 63.7 (2947) & $59.8(5208)$ \\
\hline & Missing & & $0.1(2)$ & & $0.4(14)$ & & & \\
\hline \multirow[t]{3}{*}{ Educational attainment level } & Third & $21.4(724)$ & $23.7(890)$ & $27.6(930)$ & $32.5(1051)$ & $32.6(1665)$ & 38.5 (1779) & $41.5(3610)$ \\
\hline & Secondary & 41.7 (1407) & $43.9(1648)$ & $43.4(1464)$ & $42.5(1388)$ & $51.6(2631)$ & $49.4(2287)$ & 45.6 (3968) \\
\hline & Primary & $36.7(1244)$ & $32.3(1213)$ & $29.1(980)$ & $24.7(800)$ & $15.8(808)$ & $12.1(561)$ & $13.0(1129)$ \\
\hline
\end{tabular}

${ }^{*}$ Different physical inactivity questionnaires were used-IPAQ ${ }^{17}$ in $\mathrm{NI}$ and Godin ${ }^{18}$ in Rol.

tMeasures of educational inequality as defined by SII and RII for smoking, diabetes, obesity and physical inactivity by gender in $\mathrm{NI}$ and in Rol for available survey years and trend over time.

BMI, body mass index; IPAQ, International Physical Activity Questionnaire; NI, Northern Ireland; RII, Relative Index of Inequality (rate ratio); Rol, the Republic of Ireland; SII, Slope Index of

Inequality (rate difference). 
Table 3 Measures of educational inequality as defined by SII and RII for smoking, diabetes, obesity and physical inactivity by gender in $\mathrm{NI}$ and Rol for available survey years and trend over time

\begin{tabular}{|c|c|c|c|c|c|c|c|c|c|c|c|c|}
\hline & & & 1997 & 2001 & $2005 / 2006$ & $2010 / 2011$ & Trend* & & 1998 & 2002 & 2007 & Trend* \\
\hline & & & \multicolumn{5}{|c|}{ Northern Ireland } & \multicolumn{5}{|c|}{ Republic of Ireland } \\
\hline \multirow[t]{8}{*}{ Males } & \multirow[t]{2}{*}{ Smoking } & SII & 32.7 & 38.7 & 33.5 & 36.2 & 0.90 & SII & 24.1 & 18.7 & 22.8 & 0.92 \\
\hline & & RII & 2.4 & 4 & 3.8 & 4.5 & 0.01 & RII & 2.0 & 2.1 & 2.1 & 0.64 \\
\hline & \multirow[t]{2}{*}{ Diabetes } & SII & 2.3 & 2.9 & 3.3 & 4.8 & 0.18 & SII & -0.8 & 2.2 & $\mathrm{~N} / \mathrm{A}$ & 0.01 \\
\hline & & RII & 2.4 & 2.4 & 2.5 & 2.5 & 0.90 & RII & 0.3 & 3.2 & N/A & 0.01 \\
\hline & \multirow[t]{2}{*}{ Obesity } & SII & -6.6 & $\mathrm{~N} / \mathrm{A}$ & 7.5 & 2.3 & 0.09 & SII & 6.9 & 21.3 & 8.3 & 0.73 \\
\hline & & RII & 0.8 & $\mathrm{~N} / \mathrm{A}$ & 1.4 & 1.1 & 0.36 & RII & 1.7 & 3.2 & 1.5 & 0.29 \\
\hline & \multirow[t]{2}{*}{ Physical inactivity } & SII & N/A & 10.7 & 32.6 & 20.2 & 0.13 & SII & 16.5 & 27.7 & 12.8 & 0.63 \\
\hline & & RII & $\mathrm{N} / \mathrm{A}$ & 1.3 & 2.0 & 1.8 & $<0.01$ & RII & 1.3 & 1.5 & 1.2 & 0.65 \\
\hline \multirow{8}{*}{ Females } & \multirow{2}{*}{ Smoking } & SII & 35.5 & 35 & 37.4 & 34.8 & 0.95 & SII & 27.6 & 27.5 & 27.3 & 0.69 \\
\hline & & RII & 3.5 & 3.5 & 4.6 & 4.2 & 0.14 & RII & 2.2 & $3.9 \ddagger$ & $2.8 \mp$ & 0.02 \\
\hline & \multirow[t]{2}{*}{ Diabetes } & SII† & 2.2 & 3.3 & 2.5 & 3.7 & 0.18 & SII & 2.1 & 3.4 & $\mathrm{~N} / \mathrm{A}$ & 0.54 \\
\hline & & RII & 2.9 & 8.8 & 2.3 & 2.4 & 0.37 & RII & 7.4 & 8.9 & N/A & 0.71 \\
\hline & \multirow[t]{2}{*}{ Obesity } & SII & 6.3 & $\mathrm{~N} / \mathrm{A}$ & 12.7 & 16.2 & 0.61 & SII & 16.0 & 28.2 & 6.9 & $<0.01$ \\
\hline & & RII§ & 1.5 & $\mathrm{~N} / \mathrm{A}$ & 1.6 & 2.1 & 0.90 & RII & 4.2 & 8.2 & 1.7 & $<0.01$ \\
\hline & \multirow[t]{2}{*}{ Physical inactivity } & SII & $\mathrm{N} / \mathrm{A}$ & 21.1 & 30.9 & 12.9 & 0.12 & SII§ & 23.3 & 20.2 & $16.5 \ddagger$ & 0.33 \\
\hline & & RII & $\mathrm{N} / \mathrm{A}$ & 1.5 & 1.9 & $2.4 \ddagger$ & 0.92 & RII§ & 1.4 & 1.3 & $1.3 \ddagger$ & 0.56 \\
\hline
\end{tabular}

${ }^{*}$ Test for trend in SII/RII (significant difference in SII/RII if $p$ value of ridit $\times$ survey year interaction term $<0.05$ ).

†Model fitted using Ordinary Least Squares regression with robust SEs ${ }^{22}$ due to non-convergence of generalised linear model with identity function.

$\ddagger$ Significant gender difference in SII/RII in survey year ( $\$$ significantly greater inequality in females— $-p$ value of riditxgender interaction term $<0.05$ ).

§Significant gender difference in SII/RII over time (\$ significantly greater inequality in females- $p$ value of riditxgender×survey year interaction term <0.05).

N/A, not available; NI, Northern Ireland; RII, Relative Index of Inequality (rate ratio); Rol, the Republic of Ireland; SII, Slope Index of Inequality (rate difference).

period. Despite evidence that absolute and relative inequalities in NI for obesity in men have declined more recently (between 2005/2006 and 2010/2011) widening relative and absolute inequalities occurred for obesity in men and women over the entire study period. For obesity, relative inequalities in NI increased more in women than men over time ( $p$ value for ridit of survey year $\times$ gender $\times$ ridit score was 0.05 for RII).

Absolute and relative inequalities for diabetes widened in RoI (between 1998 and 2002) with the least educated women estimated to have a ninefold higher diabetes prevalence. For obesity in men in RoI, absolute inequalities widened and relative inequalities narrowed. Encouraging trends for obesity levels in women in RoI were observed with inequalities narrowing significantly between the least and most educated for SII $(p<0.01)$ and RII $(\mathrm{p}<0.01)$.

\section{Physical inactivity}

In NI, for physical inactivity, absolute inequalities increased for men but decreased for women over the study period and relative inequalities decreased for men $(\mathrm{p}<0.01)$ and women. Relative inequalities for physical inactivity in NI were significantly higher in women compared with men in 2010/2011 $(\mathrm{p}<0.01)$.

In RoI, men reported significant higher levels of physical inactivity compared with women in 2007 for RII $(\mathrm{p}=0.04)$ and for SII $(\mathrm{p}<0.03)$.

\section{DISCUSSION}

This study examined time trends in the prevalence of key cardiovascular risk factors in relation to measures of educational attainment between two countries on the same island. ${ }^{23}$ Over the study period, the prevalence of diabetes and obesity increased overall and across strata of educational attainment in both countries, and those with lower levels of educational attainment tending to have higher prevalence of these risk factors. Overall, smoking levels and physical inactivity levels decreased in all educational strata over time in both countries. However, in NI, for both genders, there were increases in relative inequalities for obesity and smoking. Absolute inequalities increased for all risk factors in Northern Irish men and increased for diabetes and obesity in Northern Irish women. In the RoI, gender differences were observed with greater inequality for smoking, diabetes, obesity and physical inactivity in women compared with men. However, these inequalities appear to decrease over time for obesity and physical inactivity in the RoI.

As in other westernised populations, improvements in overall life expectancy in the last number of decades have occurred in conjunction with a widening gap in life expectancy between socioeconomic groups. ${ }^{24} \mathrm{~A}$ recent study in Scotland has reported on how inequalities in CVD risk factors have persisted and are likely to have contributed to recent levelling-off in CHD mortality. ${ }^{25}$ Recently reported adverse trends in obesity and diabetes 
(to 2002 in RoI) led to additional CHD deaths in Ireland, ${ }^{1}{ }^{2}$ have not diminished as evidenced by data reported in the current study. These unfavourable trends in obesity and diabetes may partly explain the recent slowing down in CHD mortality in younger persons in NI and, to some extent, stroke mortality in the RoI. ${ }^{4}$

There are established socioeconomic gradients in smoking, ${ }^{26}$ obesity ${ }^{27}$ and diabetes across NI and RoI. ${ }^{28}$ The extent of inequality for women, in particular, is greater in Northern European countries including the UK and RoI compared with Southern European countries. ${ }^{29}$ Life expectancy is greater for women and research suggests that men's health is most affected by other social determinants such as job security. ${ }^{30}$ In RoI, the overall age standardised all-cause mortality rate for men was $54 \%$ higher than for women. ${ }^{14}$

Population-level 'primordial' prevention measures impacting on changes in smoking prevalence in NI and RoI included the introduction of the smoking ban in public places, in April 2007 and March 2004 respectively, and continued taxation of tobacco products. The food standards agency in NI and the Food Safety Authority in RoI sets voluntary 'standards' for levels of saturated fats, salts and recommended portion size of sugary based products produced by industry. Arguably these voluntary agreements are a poor second best solution for regulation in the food sector when many scientists foresee greater potential impacts with enforced ingredient controls. ${ }^{31}$ Prevention in primary care was given a boost in NI in the last decade with the introduction of the Quality and Outcomes Framework (QOF) which includes identifying individuals with high cardiovascular risk and has improved identification and management of persons with type 2 diabetes. ${ }^{32}$ However, targeting high-risk populations in this way has been shown to widen health inequalities in contrast to population-wide GVD prevention strategies. ${ }^{33}$ Some have argued that 'structural' solutions (eg, through legislation) that impact on whole population averages and norms, rather than interventions that rely on individual agency (like QOF) have a better chance of addressing inequalities, while the latter type of intervention may risk intervention generated inequality. ${ }^{34} 35$

In NI greater importance is being placed on increasing physical activity in children and to increase active travel. ${ }^{9}$ Recently, the first ever national physical activity plan was launched in RoI with the target to increase the number of people taking regular exercise by $1 \%$ per year over the next 10 years, with healthier lifestyles promoted in all schools. In NI and RoI, dedicated cross departmental initiatives aimed at preventing and addressing overweight and obesity with a specific emphasis on childhood obesity have been instigated ${ }^{36}$ which acknowledge the importance of interventions throughout the life course to reduce inequalities in health. Latterly, this has included structural interventions (such as improving cycling infrastructure) to improve rates of active travel ${ }^{37}$ which we know impacts on BMI. ${ }^{38}$ In RoI a national task force on obesity was introduced in 2005, followed by a Health Service Executive (HSE) framework for Action on Obesity (2008-2012). ${ }^{39}$ Along with the policy document on cardiovascular health, a policy on physical activity guidelines was issued by the Department of Health and Children in $2009^{40}$ and a plan devised to tackle the rising obesity levels. In 2011, the Health Minister in RoI set up a Special Action Group on Obesity to examine and progress a number of issues to address the problem of obesity.

Joined up 'all island' approaches to combat inequalities, underpinned by addressing the social determinants of health have relatively recently been introduced with the objective of informing future policy initiatives ${ }^{30}$ to address the unique inequality challenges in each country and our type of analysis might provide a framework for their future evaluation. However, a key inference from our analysis must surely be that reversing inequalities in these risk factors is a long-term endeavour. There are clearly no single short-term solutions and distinct policies may be necessary or better suited to address relative and absolute inequalities.

\section{Strengths and limitations}

Our study assesses prevalence of specific cardiovascular risk factors, stratified by educational level, based on comparable nationally representative health surveys. The reporting of relative and absolute inequalities provides a comprehensive assessment of socioeconomic trends in cardiovascular risk factors accounting for changes in the population distribution of educational attainment.

The analyses included only those aged between 20 and 69 years as educational attainment data were unavailable for older groups in NI. Recent data from the RoI data are currently only becoming available to assess the impact of the unprecedented duration of European union (EU) austerity measures on health inequality trends in RoI. Social circumstances in childhood are associated with increased risk of $\mathrm{CHD},{ }^{41}$ however, parental educational attainment or social status is not typically recorded in cross-sectional studies. There were few or no standardised measurements of blood pressure and cholesterol levels across the survey years and countries. Data for smoking, physical inactivity and obesity (RoI only) and diabetes (RoI only) are based on self-reported information and survey respondents often answer questions in a socially desirable way. However, a number of studies have shown the validity of self-reported risk factors, across educational subgroups, to be high. ${ }^{42}$ However, others have suggested an underestimation of BMI, particularly in the lower socioeconomic groups, which may have influenced the findings in our study. ${ }^{43}$ Although the response rate was $>60 \%$, we have no information available about the educational status of nonrespondents. Previous studies have shown that such surveys tend to slightly over-represent those categorised in the highest socioeconomic class. ${ }^{44}$ If this is the case, 
and the excluded cases from lower socioeconomic groups were to have even more adverse risk factor profiles, then we may have underestimated inequalities in our study. However, our findings accord well with broader international comparisons which have adopted similar methods for studying trends in absolute and relative inequality in CVD incidence ${ }^{45}$ but it should be noted that a substantial proportion of the educational differentials in incidence is not explained by trends in risk factors (or indeed case fatality).

\section{CONCLUSIONS}

In conclusion, we found strong evidence of persisting and increasing magnitude of absolute and relative educational inequalities in both countries, with NI experiencing a greater widening of inequalities than RoI and important gender differences. Further completed and ongoing national surveys, in NI and RoI, will provide additional insights into whether these trends are continuing. Our findings provide partial explanations for widening inequalities in CHD mortality and therefore provide insights for decision makers on the impact of policies on reducing health inequalities.

Contributors $\mathrm{JH}, \mathrm{ZK}, \mathrm{KB}$ and FK were involved in the conception and design of this study. JH carried out the analysis. JH drafted the manuscript. JH, ZK, $\mathrm{KB}$ and FK provided advice on interpretation, and revised and edited the manuscript. All the authors read and approved the manuscript.

Funding The study was supported by the Centre of Excellence for Public Health NI.

Ethics approval The Rol health surveys, SLÁN 1998 and SLÁN 2002, were approved by the Faculty of Public Health Medicine, Royal College of Physicians of Ireland and SLÁN 2007 was approved by the Research Ethics Committee of the Royal College of Surgeons of Ireland.

Competing interests None declared.

Provenance and peer review Not commissioned; externally peer reviewed.

Data sharing statement No additional data are available.

Open Access This is an Open Access article distributed in accordance with the Creative Commons Attribution Non Commercial (CC BY-NC 4.0) license, which permits others to distribute, remix, adapt, build upon this work noncommercially, and license their derivative works on different terms, provided the original work is properly cited and the use is non-commercial. See: http:// creativecommons.org/licenses/by-nc/4.0/

\section{REFERENCES}

1. Hughes J, Kee F, O'Flaherty M, et al. Modelling coronary heart disease mortality in Northern Ireland between 1987 and 2007: broader lessons for prevention. Eur J Prev Cardiol 2013;20:310-21.

2. Kabir Z, Perry IJ, Critchley J, et al. Modelling Coronary Heart Disease Mortality declines in the Republic of Ireland, 1985-2006. Int J Cardiol 2013;168:2462-7.

3. Huovinen E, Härkänen T, Martelin T, et al. Predicting coronary heart disease mortality--assessing uncertainties in population forecasts and death probabilities by using Bayesian inference. Int J Epidemiol 2006;35:1246-52.

4. Bennett $\mathrm{K}$, Hughes J, Jennings $\mathrm{S}$, et al. Comparing the decline in coronary heart disease and stroke mortality in neighbouring countries with different healthcare systems. Heart 2013;99:1179-84.

5. Björck L, Rosengren A, Bennett K, et al. Modelling the decreasing coronary heart disease mortality in Sweden between 1986 and 2002. Eur Heart J 2009;30:1046-56.
6. Mackenbach JP. Can we reduce health inequalities? An analysis of the English strategy (1997-2010). J Epidemiol Community Health 2011;65:568-75.

7. Mackenbach JP, Bos V, Andersen O, et al. Widening socioeconomic inequalities in mortality in six Western European countries. Int J Epidemiol 2003;32:830-7.

8. Kenway, P, Maclnnes, T, Kelly, A et al. Monitoring Poverty and Social Exclusion in Northern Ireland. York: Joseph Rowntree Foundation, 2006.

9. Fit and Well, Changing Lives 2012-2022. Department of Health, Social Services and Public Safety, Northern Ireland 2012.

10. Davies J.K., Sheriff N.S. Assessing public health policy approaches to level-up the gradient in health inequalities: the Gradient Evaluation Framework. Public Health 2014;128:246-53.

11. Quality and fairness: A health system for you. http://www. drugsandalcohol.ie/11836/1/DOHC_Health_strategy_summary.pdf (accessed 7 Jul 2016).

12. Office for Social Inclusion. http://www.socialinclusion.ie/documents NAPinclusionReportPDF.pdf (accessed 7 Jul 2016).

13. Yarnell J, Yu S, McCrum E, et al; PRIME study group. Education, socioeconomic and lifestyle factors, and risk of coronary heart disease: the PRIME Study. Int J Epidemiol 2005;34:268-75.

14. Balanda K, Wilde J. Inequalities in Mortality 1989-1998: A Report on All-Ireland Mortality Data. Dublin: Institute of Public Health in Ireland, 2001.

15. Scarborough $\mathrm{P}$, Morgan RD, Webster $\mathrm{P}$, et al. Differences in coronary heart disease, stroke and cancer mortality rates between England, Wales, Scotland and Northern Ireland: the role of diet and nutrition. BMJ Open 2011;1:e000263.

16. Van Lente E, Barry MM, Molcho M, et al. SLÁN 2007: Survey of Lifestyle, Attitudes \& Nutrition in Ireland. Main Report. Dublin: Department of Health and Children, 2008.

17. Craig CL, Marshall AL, Sjöström M, et al. International Physical Activity Questionnaire: 12-country reliability and validity. Med Scl Sports Exerc 2003;35:1381-95.

18. Godin G. The Godin-Shephard Leisure-Time Physical Activity questionnaire. Health Fit J Can 2011;4:18-22.

19. World Health Organization. Physical Status: The Use and Interpretation of Anthropometry. Geneva, Switzerland: World Health Organization, 1995. WHO Technical Report Series.

20. Galobardes B, Shaw M, Lawlor DA, et al. Indicators of socioeconomic position (part 1). J Epidemiol Community Health 2006;60:7-12.

21. Ernstsen L, Strand BH, Nilsen SM, et al. Trends in absolute and relative educational inequalities in four modifiable ischaemic heart disease risk factors: repeated cross-sectional surveys from the Nord-Trondelag Health Study (HUNT) 1984-2008. BMC Public Health 2012;12:266.

22. Cheung YB. A modified least-squares regression approach to the estimation of risk difference. Am J Epidemiol 2007;166:1337-44.

23. Conry MC, Morgan K, Curry P, et al. SLÁN 2007: Survey of Lifestyle, Attitudes and Nutrition in Ireland. 'One Island-One Lifestyle?' Health and lifestyles in the Republic of Ireland and Northern Ireland: Comparing the population surveys SLÁN 2007 and NIHSWS 2005. Dublin: Department of Health and Children, 2009.

24. Wilson, R. and Oliver, Q. A Picture of Health? Tackling health inequalities in Northern Ireland. Belfast: Democratic Dialogue and Stratagem, 2007.

25. Hotchkiss JW, Davies CA, Gray L, et al. Trends in adult cardiovascular disease risk factors and their socio-economic patterning in the Scottish population 1995-2008: cross-sectional surveys. BMJ Open 2011;1:e000176.

26. Charafeddine R, Demarest S, Van der Heyden J, et al. Using multiple measures of inequalities to study the time trends in social inequalities in smoking. Eur J Public Health 2013;23:546-51.

27. El-Sayed AM, Scarborough P, Galea S. Unevenly distributed: a systematic review of the health literature about socioeconomic inequalities in adult obesity in the United Kingdom. BMC Public Health 2012;12:18.

28. Kumari M, Head J, Marmot M. Prospective study of social and other risk factors for incidence of type 2 diabetes in the Whitehall II study. Arch Intern Med 2004;164:1873-80.

29. Cavelaars AE, Kunst AE, Geurts JJ, et al. Educational differences in smoking: international comparison. BMJ 2000;320:1102-7.

30. Farrell C, McAvoy H, Wilde J; Combat Poverty Agency. Tackling Health Inequalities-An All-Ireland Approach to Social Determinants. Dublin: Combat Poverty Agency/Institute of Public Health in Ireland, 2008.

31. Laverty AA, Capewell S, Millett C. Regulation and the food industry. Lancet 2013;381:1901. 
32. Calvert M, Shankar A, McManus RJ, et al. Effect of the quality and outcomes framework on diabetes care in the United Kingdom: retrospective cohort study. BMJ 2009;338:b1870.

33. Capewell S, Graham H. Will Cardiovascular disease prevention widen health inequalities? PloS Med 2010;7:e1000320.

34. McGill R, Anwar E, Orton L, et al. Are interventions to promote healthy eating equally effective for all? Systematic review of socioeconomic inequalities in impact. BMC Public Health 2015;15:457.

35. Adams J, Mytton $\mathrm{O}$, White $\mathrm{M}$, et al. Why are some population interventions for diet and obesity more equitable and effective than others? The role of individual agency. PLoS Med 2016;13: e1001990.

36. Get Ireland Active. Fit Futures: Focus on Food, Activity and Young People. Dublin: Department of Health and Children, Health Service Executive, 2009.

37. Making Life Better Belfast Strategic Plan. Belfast Active Travel Action Plan 2014-2020. Focussing on Inequalities. Public Health Agency. http://www.publichealthagency.org/sites/default/files/ 181114\%20Active\%20Travel\%20Action\%20Plan.pdf

38. Martin A, Panter J, Suhrcke M, et al. Impact of changes in mode of travel to work on changes in body mass index: evidence from the British Household Panel Survey. J Epidemiol Community Health 2015;69:753-61.
39. Health Service Executive. HSE Framework for Action on Obesity 2008-2012, 2010.. http://www.thehealthwell.info/node/52589 (accessed 7 Jul 2016).

40. Department of Health and Children, Health Service Executive The National Guidelines on Physical Activity for Ireland. 2009. http:// health.gov.ie/wp-content/uploads/2014/03/active_guidelines.pdf (accessed 7 Jul 2016).

41. Brunner E, Shipley MJ, Blane D, et al. When does cardiovascular risk start? Past and present socioeconomic circumstances and risk factors in adulthood. J Epidemiol Community Health 1999;53:757-64.

42. Kenny Gibson W, Cronin H, Kenny RA, et al. Validation of the self-reported hearing questions in the Irish Longitudinal Study on Ageing against the Whispered Voice Test. BMC Res Notes 2014;7:361.

43. Ljungvall Å, Gerdtham UG, Lindblad U. Misreporting and misclassification: implications for socioeconomic disparities in body-mass index and obesity. Eur J Health Econ 2015;16:5-20.

44. Demarest S, Van der Heyden J, Charafeddine R, et al. Socio-economic differences in participation of households in a Belgian national health survey. Eur J Public Health 2012;23;981-5.

45. Veronesi G, Ferrario MM, Kuulasmaa K, et al. Educational class inequalities in the incidence of coronary heart disease in Europe: the MORGAM Project Cohort Component. Heart 2016;102:958-65. 